\title{
Key Determinants of Waste Separation Intention among Students on Campus
}

\author{
Siti Fadzilah Ayob1, a and Low Sheau-Ting ${ }^{2}$ \\ ${ }^{1}$ Department of Real Estate, Faculty of Geoinformation and Real Estate, Universiti Teknologi Malaysia, 81310 Skudai, Johor, Malaysia \\ ${ }^{2}$ Centre of Real Estate Studies, Institute for Smart Infrastructure and Innovative Construction, Universiti Teknologi Malaysia, 81310 Skudai, \\ Johor, Malaysia
}

\begin{abstract}
This study aims to identify the key determinants of waste separation intention among the students in Universiti Teknologi Malaysia (UTM). As reported in World Bank Report, generation of global municipal solid waste are approximately 1.3 billion tonnes per year, and it will increase approximately 2.2 billion tonnes per year by 2025 . Similar trend in Malaysia which approximately eight million tonnes of municipal solid waste is produced daily. Upward trend of the solid waste generated is contributed by various forces including growth, increase of population, residents attitude and rapid urbanisation in the country. Considering the negative impacts from increase of waste generated in the country such as environmental degradation, separate the waste at its source can increase recycling rate and hence reduce waste generation. In the $11^{\text {th }}$ Malaysia Plan, the government has urged the nation to actively practice waste separation. Understanding the determinants influencing waste separation behaviour can lead to effective waste reduction among the targeted group. This study adopted the Theory of Planned Behaviour as the fundamental framework. The key determinants of waste separation behaviour are attitude, subjectives norm, and perceived behavioural control. An elicitation survey has been conducted to explore the students's beliefs relative to the waste separation behaviour. The empirical data collected were analysed using structural equation modelling (SEM) assisted by SmartPLS software. The result shows that only determinants are significant towards intention which are attitude and Perceived Behavioural Control while Subjective Norm is not. The results of the study is significance to the organisation as identification of the determinants that influence waste separation intention contributes to a more focused waste separation programme that allign to Malaysia's objective towards a sustainable developing country.
\end{abstract}

\section{Keywords: structural equation modelling, theory of planned behaviour, waste separation}

\section{$1 \quad$ Introduction}

Developing countries including Malaysia faced with low quality of environment especially in urban areas which respect to the solid waste management sector $[23,36]$. As stated by [18], one of the factors contributes to the low environment quality is inadequate and unscientific municipal solid waste management practice. Application of 3 Rs should be done in developing countries in order to improve the solid waste management [8, 14]. Malaysia also facing the solid waste problem because of the economic growth, increase of population, residents attitude $[7,36]$ and rapid urbanisation [27]. Malaysia government had launched many types of recycle programs, campaign and provide solid waste facilities in order to improve solid waste management sector but the success rate is still low based on the increasing amount of waste generated from year to year [35]. This is because people are not practicing the waste recycling behaviour although they have the knowledge and awareness in improper waste management to the environment $[27,28]$. Therefore, in 11th Malaysia Plan, the government focuses on changing the nation's behaviour in minimising waste through waste separation instead of providing extra landfill and dumping area [30]. Waste separation is one of the ways to reduce amount of waste being dumped at the landfill and increase the recycle rate $[7,31]$. In this RMK11, government focus in fostering

\footnotetext{
a Siti Fadzilah Ayob: fadz91@gmail.com
} 
waste separation behaviour among the society through any comprehensive activities and willing to invest more as the waste issue is at critical stage. Therefore, government came out with A2 strategy in RMK11 which emphasis changing Malaysian behaviour especially in waste separation which had been launched on $1^{\text {st }}$ September 2015. In recent, a program called "Separation of Solid Waste at Source" was launched on $1^{\text {st }}$ September 2015 to implement the mandatory separation of waste at source in few states of Malaysia. Besides of government efforts, there are also some research had been conducted in order to help in reducing the number of waste generated in the country. For example study conducted by [11] which emphasis on benefit-cost analysis on the economic feasibility of construction waste minimisation, [14] which focuses on solid waste management and other research which focus on food waste separation $[17,19,24,29]$. Based on the literatures, it is noticed that there is less research had been conducted whether in Malaysia or other country on solid waste separation compare to industrial waste separation, food waste separation and household waste separation. Therefore, present study that exploring the solid waste separation intention is conducted to contribute to the existing solid waste separation literatures.

Based on previous research, most of the waste management is handled by behavioural conduct. This is indicating that improving human behaviour contributing to the success of waste management program. Therefore, improving human behaviour towards waste minimisation through waste separation is essential. In order to change the human behaviour, it is important to identify the key determinants of behaviour because human behaviour can be improved or change if the right determinants that formulate specific behaviour being identified [25,40, 41]. In waste separation context, identify the key determinants of waste separation behavior is critical for sustainable behavior change. By having the right key determinants of behaviour, government can come out with more comprehensive strategy and programs that can lead to behavioural change on waste separation which will help the government to achieve objective in minimising the waste. Therefore, it is important to get the right determinants in formulating the nation's waste separation behaviour effectively. Hence this study aims to identify the key determinants of waste separation intention so that it can be used to foster waste separation behaviour among the nation and as well as reducing the number of waste generated which align with Malaysia's objective in achieving a sustainable developing country.

\section{Theory Of Planned Behaviour}

Waste should be separated before being recycled [10, 32]. Therefore, waste separation comes at early stage before recycling such as sorting out the waste into its specific material which is paper, glass, and plastics. However, waste separation is likely to be difficult and several factors may be taken into consideration. In identifying the factors which influencing waste separation decision, the Theory of Planned Behaviour (TPB) can be used as it provides a systematic theoretical framework and there are many previous studies prove that TPB is very useful in investigating the determinants of specific intention and behaviour [33, 39]. According to Downs and Hausenblas (2005), the TPB explains that human's expectations and values about involving in behaviour form their behavioural, normative, and control beliefs. These will lead to intention and behaviour through their attitude, subjective norm, and perceived behavioural control. Based on the $\mathrm{TPB}$, the three determinants in performing behaviour are attitude towards behaviour, subjective norm (SN) and perceived behavioural control (PBC) [4]. According to [1], the first determinant is the attitude, which will form the intention of an individual whether to participate or not in specific behaviour. The second measure is the subjective norm, which refers to social influence in influencing an individual whether to perform or refuse to perform the specific behaviour and the last antecedent is the perceived behavioural control, which is explaining one's selfconfidence whether the individual is able to perform the behaviour or no. For the attitude towards waste separation, of which a positive evaluation such as "waste separation will help in increasing the recycle rate" or "waste separation contributes to cleaner environment" is likely to increase the intention to practice waste separation activities and thus, this will lead to performing on waste separation behaviour. In contrast, a negative attitude such as "I feel that waste separation is wasting my time" will ultimately lead to a lower likelihood of waste separation intention and behaviour.

The second determinant of waste separation intention is the subjective norm. Based on the TPB, individual will take action to separate waste if their important referents think they should participate in waste separation and vice versa. For example "I think my friends in the university always want me to engage in waste separation activities" and "I think my lecturer will be happy to know I am practicing waste separation behaviour". Such approval perception from their important referent will contribute to a higher waste separation intention and behaviour. However, if their important referent makes the individual think that they disapprove their action, students will be less likely to practice the specific action to separate waste, such as "My friends in the hostel will tease me if I put the waste into the bins according to its colour to separate waste".

The third key determinant of waste separation intention is perceived behavioural control. This means that if the individual has high self-confidence in their ability to separate waste, it will increase their intention to do waste separation. This also means if the individual has low self- 
confidence on their ability to practice waste separation, they will not have the intention to perform waste separation. For instance, a student who is confident that he could separate waste before throwing the waste possesses higher waste separation intention that the one who does not believe that he will separate the waste before throwing the waste as he is a busy person. The student with higher confidence level is more likely to have intention to perform waste separation than the latter. According to TPB, an intention to engage a behaviour will happen when people make a positive evaluation of the behaviour, has pressure from the social and also they believe that they have the opportunity to do so [2].

Various studies conducted to test the applicability of TPB across various type of behaviour [25]. The most relevant study are [26] which study on the determinants of recycling intention behaviour among the Malaysian school students: an application of theory of planned behaviour [39] which conduct a study on recycling attitude and behaviour in university campus in Hong Kong. Other than that, there are also few studies that adopted TPB in recycling context $[19,22,13]$.

\section{$3 \quad$ Research Methodology}

This section will discuss on the application of research methods and the data sample requirements that suit the objective of the study. This study employed Structural Equation Modelling (SEM) assisted by SmartPLS to examine the causal relationship between the determinants towards waste separation intention. TPB is adopted as the theoretical structure. Based on the literature review, it is discovered that the TPB model comes together with hypotheses. In this study, there are three hypotheses are proposed. The hypotheses are: (1) Attitude has a positive influence on waste separation intention; (2) SN has a positive influence on waste separation intention, and (3) $\mathrm{PBC}$ has a positive influence on waste separation intention. Two step modelling was performed in this study. First step is establishing the measurement model, where the measurement model is revised and confirmed. Second step is test the structural model, where the direct relations among latent variables were modelled. The proposed model was evaluated and demonstrated a poor model fit which lead to subsequent modification of the model.

\subsection{Research instrument}

This research is a quantitative study using a survey design. The questionnaire was designed based on previous research that applied TPB in pro- environmental behavior $[33,37,42]$ and the results from elicitation study. An elicitation study was conducted in UTM to gather students's important exercise and the responses with high frequency were used in constructing measures in final questionnaire [3]. In structural equation modeling, a distinction is made between single item variable and variables computed from multiple items. Single item variables are referred to as observed variables, while multi item variables are called latent variables. In this study there were four independent variables consisting of four latent variables: attitudes, subjective norms, perceived behaviour control and behaviour intention. The questionnaire composed of two section, which the first section is respondent demographic profile and the second section is to assess students' attitude, subjective norm, and perceived behavioural towards the solid waste separation intention based on Theory of Planned Behaviour.

The questionnaire consisted of 19 questions distributed into four dimensions: attitude (6 questions), subjective norm (3 questions, perceived behavioural control (6 questions) and intention towards solid waste separation (4 questions). The questionnaire is a closed-ended questionnaire with the responses guided on a range of given scales. The reliability of the instrument is based on Cronbach Alpha value which is 0.851 .

\subsection{Research procedures}

The population in this study is all students from Universiti Teknologi Malaysia (UTM) because it is one of the largest public universities in Malaysia and it is easy access in for this study. The student population in UTM is about 24,000 students as reported in UTM official web portal, and by referring to the table for determining sample size developed by Krejcie and Morgan (1970), the minimum sample needed is 378 . However, in order to get more generalized data for this research, 486 of responses were gathered. The overall response was approximately $97.2 \%$. The responses consist of equal number of students regarding of their gender, nationality and academic qualification. The samples chosen based on convenience sampling method that is selected based on ease of access. The questionnaire is distributed face-to-face to the students in the university after revised based on the comments from questionnaire pretesting.

\section{$4 \quad$ Findings And Discussion}

The initial structural model consists of 3 main paths which are ATT-INT (path coefficient $(\mathrm{E})=0.613$, Composite Reliability $(\mathrm{CR})=0.844$, Average Variance Extracted $(\mathrm{AVE})=0.483), \mathrm{SN}-\mathrm{INT}(\mathrm{E}=0.008, \mathrm{CR}=0.693, \mathrm{AVE}=$ $0.460)$ and PBC-INT $(\mathrm{E}=0.270, \mathrm{CR}=0.706$, AVE $=$ 0.378). The initial model is not fit because some of AVE and $\mathrm{CR}$ are not significant as the significant value for AVE should greater than 0.5 and CR should greater than 0.7 . The initial structural model was modified to improve the model fit. The revised structural model produced a better fit ATTINT $(\mathrm{E}=0.688, \mathrm{CR}=0.856, \mathrm{AVE}=0.545), \mathrm{SN}-\mathrm{INT}(\mathrm{E}=$ $0.030, \mathrm{CR}=0.747, \mathrm{AVE}=0.618)$ and $\mathrm{PBC}-\mathrm{INT}(\mathrm{E}=0.179$, $\mathrm{CR}=0.825, \mathrm{AVE}=0.543$ ). Based on the bootstrapping calculation, the T-value shows only two determinants have positive relationship towards intention. Hypothesis 1 (ATT 
-> INT): Attitude has a positive influence on waste separation intention has T-value of $20.260(p<0.001)$, and PBC -> INT: Perceived behavioural control has a positive influence on waste separation intention has T-value of $4.976(\mathrm{p}<0.01)$. However, for the second hypothesis, (SN $>$ INT): Subjective norm do has a positive influence on waste separation intention has T-value of -1.056 ( $p$ $=0.267$ ).

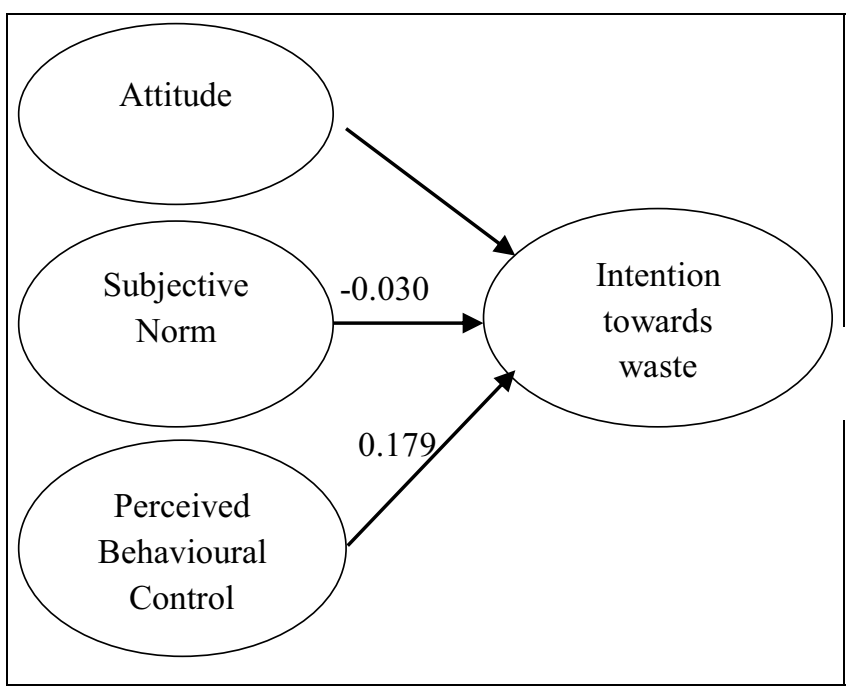

Figure 1. Modified structural model of waste separation intention in UTM

The results of present study showed that attitude is the strongest predictor towards waste separation intention among the students in UTM. This finding is consistent with previous study such as study conducted by [38], which stated that the more easy to do recycle, the higher the influence to engage positive attitude. Other than that, [6] also discovered that attitude is the strongest predictor of intention in desired behaviour. It is concluded that the respondents in this study had attitudes that significantly influenced their intention as students to separate waste. This finding also suggests that the UTM students as respondents in this study, had attitude which makes them feel good whenever they do the waste separation.

Hypothesis 2 predicted that as $\mathrm{SN}$ is favourable to waste separation intention. The results did not supported hypothesis 2 . This finding is consistent with most of TPB studies. Typically the SN variable was the weakest influence on behaviour intention. In [37] and [12] the SN variable was the weakest predictor of the TPB variables. In [10] and [21], it was not significant at all. The findings in this study showed that $\mathrm{SN}$ is not significant in waste separation intention among UTM students. This is possibly true when waste separation is a public behaviour such as in the learning institution [9]. Other than that, this also shows that the lecturers, friends and classmate did not significant in influencing the students intention to do waste separation. This finding shows that one's intention to separate the waste is highly dependent on one's self and this is the main factor that makes one separate the waste not because of get support and encouragement from other people.

Hypothesis 3 predicted that as $\mathrm{PBC}$ is significant towards waste separation intention. The findings show that the PBC-INT is the second determinant that is significant towards intention. This is showing that the students in UTM are confident they can separate the waste is they wanted to. Additionally, the students do not agree on the waste separation practice is takes up too much time of them and waste of time. This result is consistent with some previous studies. For instance [39] which conduct a study on recycling attitude and behaviour in university campus in Hong Kong has found that attitude, subjective norm and perceived behavioural control influencing recycle attitude.

Multigroup analysis also had been done in order to identify whether by attending any waste separation related program will influence the respondent's waste separation intention. The result suggests that PBC-INT is the only significant different path relationship between the group that has attended waste separation related program and the group never attended any waste separation related program. This is based on the path coefficient difference shown which the value of PBC-INT is the highest among other determinants, 0.246 . Other than that, if the $\mathrm{p}$-value is smaller than 0.05 or larger than 0.95 , it shows that the determinant is significant [20]. Therefore, based on the result, the significance p-value is only shown by PBC-INT and no other determinants. The p-value for PBC-INT is 0.028 while for the ATT-INT and SN-INT are 0.720 and 0.417 respectively. This shows that by having knowledge on desired behaviour can increase the PBC towards intention. This is consistent with [37] where the knowledge of knowing how to recycle is significant towards PBC and correlated with intention.

Overall, the finding of present study is similar to some previous study such as $[21,34]$. Those previous study are using the theory of planned behaviour in identifying the relationship of attitudes, subjective norms and perceived control behaviour. These studies show that the attitudes and perceived behavioral control had significant influence on intention, while subjective norms did not have significant influence on their intention.

\section{Conclusion}

The primary purpose of this research was to determine the key determinants of waste separation intention among UTM students using TPB. The strongest predictor of intention to recycle is Attitude and PBC while $\mathrm{SN}$ is not influencing the intention to separate waste among the students. As a conclusion, UTM waste management system should focus on elements that can effectively inculcate a pro-environmental behaviour among students such as highlighting the benefits of waste separation intention and 
by providing enough facilities in order to foster waste separation intention and behaviour. However, this study only focuses on students from Universiti Teknologi Malaysia (UTM) and not other university community such as supporting staffs and academics staff. Therefore, the results will only target and applied on students' community only and cannot be generalised to other context. Other than that, this research uses self-reported data as it is a social science research. This may give biased answer during data collection. Lastly, it is recommended to include some other additional determinants in future study suits with the local context.

\section{Acknowledgements}

The authors gratefully acknowledge the research grant and financial support provided by the Ministry of Higher Education (MOHE) and University Teknologi Malaysia (UTM), under the research grant number Q.J130000.2527.11H61.

\section{References}

[1]Ajzen, I. (1991). The Theory Of Planned Behavior. Organizational Behavior And Human Decision Processes, 50(2), 179-211.

[2]Ajzen, I. (2005). Attitudes, Personality, And Behavior. Mcgraw-Hill Education (UK).

[3]Ajzen, I., \& Fishbein, M. (1980). Understanding Attitudes And Predicting Social Behaviour.

[4]Ajzen, I., \& Madden, T. J. (1986). Prediction Of GoalDirected Behavior: Attitudes, Intentions, And Perceived Behavioral Control. Journal Of Experimental Social Psychology, 22(5), 453-474.

[5]Ajzen, I., 1991. The Theory Of Planned Behaviour. Organizational Behaviour And Human Decision Processes 50, 170-211. Bartlett, J.E., Kotrlik, J.W., Higgins, C.C., 2001. Information Technology. Learning And Performance Journal 1, 943-950.

[6]Arvola, A., Vassallo, M., Dean, M., Lampila, P., Saba, A., Lähteenmäki, L., \& Shepherd, R. (2008). Predicting Intentions To Purchase Organic Food: The Role Of Affective And Moral Attitudes In The Theory Of Planned Behaviour.Appetite, 50(2), 443-454.

[7]Badgie, D. (2011). Solid Waste Management System In The Kanifing Municipal Council (KMC), The Gambia (Doctoral Dissertation, Msc. Thesis, Universiti Putra Malaysia (UPM)).

[8]Badgie, D., Samah, M. A., Manaf, L. A., \& Muda, A. B. (2012). Assessment Of Municipal Solid Waste Composition In Malaysia: Management, Practice And Challenges. Polish Journal Of Environmental Studies, 21(3), 539-547.

[9]Barr, S. Ford, N.J, Gilg, A. (2003). Attitude Towards Recycling Household Waste In Exeter,Devon:
Quantitative And Qualitative Approaches. Local Environment. 8, 407- 428 .

[10]Beedle Boldero, J., 1995. The Prediction Of Household Recycling Of Newspaper: The Role Of Attitudes, Intentions And Situational Factors. Journal Of Applied Social Psychology 25, 440e462.

[11]Begum, R. A., Siwar, C., Pereira, J. J., \& Jaafar, A. H. (2006). A Benefit-Cost Analysis On The Economic Feasibility Of Construction Waste Minimisation: The Case Of Malaysia. Resources, Conservation And Recycling, 48(1), 86-98.

[12]Davis, G., O'Callaghan, F., \& Knox, K. (2009). Sustainable Attitudes And Behaviours Amongst A Sample Of Non-Academic Staff: A Case Study From An Information Services Department, Griffith University, Brisbane. International Journal of Sustainability In Higher Education, 10(2), 136-151.

[13]De Leeuw, A., Valois, P., Ajzen, I., \& Schmidt, P. (2015). Using The Theory Of Planned Behavior To Identify Key Beliefs Underlying Pro-Environmental Behavior In High- School Students: Implications For Educational Interventions.Journal Of Environmental Psychology, 42, 128-138.

[14]Desa, A., Kadir, N. B. Y. A., \& Yusooff, F. (2011). A Study On The Knowledge, Attitudes, Awareness Status And Behaviour Concerning Solid Waste Management. Procedia-Social And Behavioral Sciences, 18, 643-648.

[15]Downs, D. S., \& Hausenblas, H. A. (2003). Exercising For Two: Examining Pregnant Women's Second Trimester Exercise Intention And Behavior Using The Framework Of The Theory Of Planned Behavior. Women's Health Issues, 13(6), 222-228.

[16]Downs, D. S., \& Hausenblas, H. A. (2005). Elicitation Studies And The Theory Of Planned Behavior: A Systematic Review Of Exercise Beliefs. Psychology of Sport And Exercise, 6(1), 1-31.

[17]Eisted, R., \& Christensen, T. H. (2011). Characterization Of Household Waste In Greenland. Waste Management, 31(7), 1461-1466.

[18]Firdaus, G., \& Ahmad, A. (2010). Management Of Urban Solid Waste Pollution In Developing Countries. International Journal of Environmental Research, 4(4), 795-806.

[19]Ghani, W. A. W. A. K., Rusli, I. F., Biak, D. R. A., \& Idris, A. (2013). An Application Of The Theory Of Planned Behaviour To Study The Influencing Factors Of Participation In Source Separation Of Food Waste. Waste Management,33(5), 1276-1281.

[20]Henseler, J., Ringle, C. M., \& Sinkovics, R. R. (2009). The Use Of Partial Least Squares Path Modeling In International Marketing. Advances In International Marketing (AIM), 20, 277-320.

[21]Huda, N., Rini, N., Mardoni, Y., \& Putra, P. (2012). The Analysis Of Attitudes, Subjective Norms, And Behavioral Control On Muzakki's Intention To Pay 
Zakah. International Journal Of Business And Social Science,3(22), 271-279.

[22]Izagirre-Olaizola, J., Fernández-Sainz, A., \& VicenteMolina, M. A. (2015). Internal Determinants Of Recycling Behaviour By University Students: A Cross-Country Comparative Analysis. International Journal Of Consumer Studies, 39(1), 25-34.

[23]Khajuria, A., Yamamoto, Y., \& Morioka, T. (2010). Estimation Of Municipal Solid Waste Generation And Landfill Area In Asian Developing Countries.

[24]Knussen, C., Et Al. (2004). An Analysis Of Intentions To Recycle Household Waste: The Roles Of Past Behaviour, Perceived Habit, And Perceived Lack Of Facilities. Journal Of Environmental Psychology 24(2): 237-246.

[25]Low S.T. (2012). Factors Affecting Energy Conservation Behaviour Of Students In Malaysia University. Ph.D. Thesis. Universiti Teknologi Malaysia [26]Mahmud SND, Osman K. (2010). The Determinants Of Recycling Intention Behavior Among The Malaysian School Students: An Application Of Theory Of Planned Behavior. Procedia Social And Behavior Sciences;9:119-24.

[27]Moh, Y. C., \& Manaf, L. A. (2014). Overview Of Household Solid Waste Recycling Policy Status And Challenges In Malaysia. Resources, Conservation And Recycling, 82, 50-61.

[28]Omran, A., Mahmood, A., Abdul Azi, H., Robinson, G.H., 2009. Investigating Household Attitude

Toward Recycling Of Solid Waste In Malaysia: A Case Study. International J Ournal Of Environmental Research 3, 275-288.

[29]Pakpour, A. H., Zeidi, I. M., Emamjomeh, M. M., Asefzadeh, S., \& Pearson, H. (2014). Household Waste Behaviours Among A Community Sample In Iran: An Application Of The Theory Of Planned Behaviour. Waste Management,34(6), 980-986.

[30]Percetakan Nasional Malaysia Berhad., RMK11. 2016. Print

[31]Poon, C. S., Ann, T. W., \& Ng, L. H. (2001). On-Site Sorting Of Construction And Demolition Waste In Hong Kong. Resources, Conservation And Recycling, 32(2), 157-172.

[32]Ramayah, T., \& Rahbar, E. (2013). Greening The Environment Through Recycling: An Empirical Study. Management of Environmental Quality: An International Journal, 24(6), 782-801.

[33]Ramayah, T., Lee, J. W. C., \& Lim, S. (2012). Sustaining The Environment Through Recycling: An Empirical Study. Journal of Environmental Management, 102, 141- 147.

[34]apingi, R., Ahmad, N., \& Mohamad, M. (2011). A Study On Zakah Of Employment Income: Factors That Influence Academics' Intention To Pay Zakah. In 2nd International Conference On Business And Economic Research (2nd ICBER 2011), Langkawi, Kedah.
[35]SWCM, (2015). http://www.ppsppa.gov.my/index. [36]Shamshiry, E., Nadi, B., \& Mahmud, A. R. (2011). Optimization Of Municipal Solid Waste Management. In Proceedings Of The 2010 International Conference On Biology, Environment And Chemistry (Vol. 1, Pp. 119-21). [37]Tonglet, M., Philips, P.S., Read, A.D., 2004. Using The Theory Of Planned Behaviour To Investigate The Determinants Of Recycling Behaviour: A Case Study From Brixworth, UK. Resources, Conservation And Recycling 41, 191-214.

[38]Tonglet, M., Phillips, P. S., \& Bates, M. P. (2004). Determining The Drivers For Householder ProEnvironmental Behaviour: Waste Minimisation Compared To Recycling. Resources, Conservation And Recycling, 42(1), 27-48.

[39]Wan, C., Cheung, R., \& Qiping Shen, G. (2012). Recycling Attitude And Behaviour In University Campus: A Case Study In Hong Kong. Facilities,30(13/14), 630-646.

[40]Wang, Z., Zhang, B., Yin, J., \& Zhang, Y. (2011). Determinants And Policy Implications For Household Electricity-Saving Behaviour: Evidence From Beijing, China. Energy Policy, 39(6), 3550-3557.

[41]Webb, T., Joseph, J., Yardley, L., \& Michie, S. (2010). Using The Internet To Promote Health Behavior Change: A Systematic Review And Meta-Analysis Of The Impact Of Theoretical Basis, Use Of Behavior Change Techniques, And Mode Of Delivery On Efficacy. Journal Of Medical Internet Research, 12(1), E4. [42]Yazdanpanah, M., Forouzani, M., \& Hojjati, M. (2015). Willingness Of Iranian Young Adults To Eat Organic Foods: Application Of The Health Belief Model.Food Quality And Preference, 41, 75-83. 